\title{
Cost-at-Risk and Benchmark Government Debt Portfolio in Korea
}

\author{
Joon-Ho Hahm* \\ Yonsei University \\ and \\ Jinho Kim $^{* *}$ \\ Ewha Womans University
}

January 2002

We are grateful to Mats Christoffersson, Clemente Del Valle, Lars Jessen, Young-Sun Koh, Inseok Shin, Xin Zhang, and seminar participants at the Korea Development Institute, Korea Fixed Income Research Institute and the World Bank for valuable comments and suggestions. The first author gratefully acknowledges financial support from the Center for International Studies, Yonsei University.

* Graduate School of International Studies, Yonsei University, 134 Shinchon-dong, Seodaemoon-gu, Seoul 120-749, Korea, E-mail: jhahm@yonsei.ac.kr

** College of Business Administration, Ewha Womans University, 11-1 Daehyun-dong, Seodaemoon-gu, Seoul 120-750, Korea, E-mail: jhkim@mm.ewha.ac.kr 


\title{
Cost-at-Risk and Benchmark Government Debt Portfolio in Korea
}

\begin{abstract}
$\underline{\text { Abstract }}$
This paper provides a framework to identify and achieve a benchmark portfolio structure for government debt based upon the trade-off between expected debt-servicecost and risk. Using actual Korean government debt data, we empirically derive the medium-term efficient frontier conditional upon the existing portfolio structure. In addition, a target benchmark portfolio is identified from the efficient frontier by employing a penalty function with cost-at-risk and duration gap as two penalty factors. The target portfolio identified also suggests an optimal borrowing policy in determining the maturity mix of government bond issuance.
\end{abstract}

JEL Classification: H6, G1, F3

Keywords: sovereign debt, government bond, benchmark portfolio, cost-at-risk, optimal debt policy 


\section{Introduction}

The need for a better sovereign debt management has been highlighted by the recent crises in emerging market countries. The government debt, including its guarantees, has been rapidly accumulating in many crisis-ridden countries, which makes the improvement of debt monitoring and risk management capacity at the sovereign level an urgent task. The ultimate objective of sovereign debt management is to minimize long-term cost of debt given the trade-off between expected debt-service-cost and risk associated with government borrowing strategies. ${ }^{1}$ To achieve the above objective, it is essential to have an effective and practically applicable benchmarking framework, which will provide a target debt portfolio structure, and against which debt managers' performance can be evaluated. ${ }^{2}$

In theory, as emphasized by Claessens et al. (1995, 1998), establishing a benchmark portfolio in the management of sovereign debt is equivalent to finding an optimal solution to dynamic stochastic problem given the stochastic processes of exogenous variables such as exchange rates and interest rates. ${ }^{3}$ This approach is also analogous to finding an optimal asset portfolio in investment theories, as developed by Markowitz (1952) and further extended by numerous authors including Merton (1971) and Breeden (1979).

While the theoretical concept of optimal benchmark portfolio has been relatively well established, practically usable benchmarking framework is not readily available. First, portfolio optimization theories typically require utility representations of aggregate preferences at the sovereign level, which are not known in reality. Second, the asset-

\footnotetext{
${ }^{1}$ For surveys of the objectives and practices of sovereign debt management in various countries, see Carracedo and Dattels (1997) and Cassard and Folkerts-Landau (1997), among others. The size and sustainability of sovereign debt are also important issues in sovereign debt management. However, the present paper focuses on the optimal structure and risk management of sovereign debt portfolios. For sustainability issues, see Cohen (1991) and Eaton (1992), among others.

${ }^{2}$ For instance, the operational objective of the Irish National Treasury Management Agency is to outperform a benchmark established in net present value terms while not exceeding the annual cash budget for interest payments on government debts. Sweden and Portugal are also employing benchmarks in the management of government debt portfolios. According to the survey conducted by the World Bank (1999), 8 out of the 38 countries surveyed answered that they are using benchmarks to measure portfolio performance on foreign and domestic sovereign debts.

3 Claessens (1992) and Kroner and Claessens (1991), for instance, applied a dynamic stochastic optimization framework to identify optimal currency structures in small open economies.
} 
liability management (ALM) framework, widely adopted in the risk management of various private institutions, cannot be directly applied at the sovereign level as typical government assets, national tax base for instance, are not in the form of financial assets. Hence, in the absence of utility functions to be optimized and counterpart asset portfolios to be matched with, it is an inherently difficult task to identify optimal structures of sovereign debt portfolios. For this reason, in most countries, actual practices of sovereign debt risk management have been limited to the quantification and monitoring of partial risk measures such as durations for interest rate risks and maturity profiles for liquidity risks, and integrated approaches based upon modern portfolio and risk management theories have rarely been applied.

The purpose of the present paper is to provide an integrated benchmarking framework, which is based upon the recent development in risk management theories and yet readily applicable to actual debt management practices. Among various aspects of a benchmark portfolio, we focus on the maturity structure of government debts and try to provide answers to the following questions: How can we characterize the trade-off between expected debt-service-cost and risk given the current structure of government debt and borrowing requirements in the future? What should be the target maturity structure of the government debt given the cost and risk trade-off above? And finally, what should be the government debt issuing policy to obtain the benchmark portfolio structure?

In the present paper, the benchmarking framework is built upon the traditional meanvariance efficient frontier approach while relatively recent concept of cost-at-risk $(\mathrm{CaR})$ is utilized to identify a target benchmark portfolio. While the efficient frontier and CaR measures are estimated from the perspective of debt-service-cost risk, the benchmarking framework is flexible enough to incorporate other factors such as liquidity risks and counter-party asset structures as additional criteria in identifying the benchmark portfolio. The plan of the paper is as follows: In the next section, the conceptual framework of the benchmarking strategy is outlined. Section 3 applies the benchmarking strategy to actual Korean sovereign debt portfolios. Both for domestic and external sovereign debt portfolios, we identify medium-term target debt structures and derive optimal borrowing mixes for the government to achieve the benchmark portfolios. Finally, section 4 summarizes and concludes. 


\section{The Conceptual Framework}

As noted by Claessens et al (1998), any portfolio optimization problem including the sovereign debt portfolio benchmarking can be represented as a variant of the following stochastic dynamic programming:

$$
\text { Minimize } E\{f(s ; d)\}, \quad \text { where } d \text { is in } D
$$

In equation (1), $d$ stands for a sequence of decisions to be made and $D$ is the set of all acceptable decisions. $E$ is an expectations operator and function $f$ is an objective function that serves as decision criteria. The value of $f$ depends upon $d$ as well as random variables $s$ that provide a description of possible future environments when the consequences of the decisions $d$ are evaluated. In a dynamic discrete time setting, where time 0 and 1 represent today and next period and so on, the above problem can be restated as follows:

$$
\begin{aligned}
& \text { Find } \quad d=\left(d^{0}, d^{1}\left(s^{1}\right), d^{2}\left(s^{1}, s^{2}\right), \ldots\right) \\
& \text { such that } \quad d^{0} \text { in } D^{0} \text {, } \\
& d^{l}\left(s^{1}\right) \text { in } D^{l}\left(s^{l} ; d^{0}\right) \text {, } \\
& d^{2}\left(s^{1}, s^{2}\right) \text { in } D^{2}\left(s^{1}, s^{2} ; d^{0}, d^{l}\left(s^{l}\right)\right), \ldots \ldots \ldots \ldots \\
& \text { which minimizes } \quad E\left\{f\left(s^{1}, s^{2}, \ldots ; d^{0}, d^{l}, \ldots \ldots\right)\right\}
\end{aligned}
$$

As noted by Kim and Hahm (2000), in the context of sovereign debt management, $d$ may correspond to decisions on the maturity structure of government debt portfolio or on the currency composition in the case of external sovereign debt. The vector of random variables $s$ may correspond to the term structure of interest rates, exchange rates, GDP growth rates and so forth. The possible choice set $D$ represents the range where decisions are restricted and reflects policy constraints such as the minimum exposure to a specific currency or the maximum percentage of refinancing. Note that the subsequent choice set $D$ in the future depends upon the realizations of random variables as well as previous decision choices. For instance, the debt portfolio structure to be realized 5 
years from now will depend upon the realizations of term structures, fiscal requirements, refinancing policies of maturing debts, and the interim borrowing mixes to finance borrowing requirements during the next 5 years.

While the control function $f$ could be specified in various forms, it necessarily involves an aspect of debt portfolio depending upon which risk is to be more actively managed. ${ }^{4}$ For instance, nominal values, market values, or debt-service-costs of the government debt can serve as arguments of the control function. The function may also involve a target risk measure summarizing the return (cost) and risk trade-off, and is often represented in the form of a penalty function. ${ }^{5}$

As the objective and horizon of the government debt management differ from those of private institutions, types of risks actively managed at the sovereign level also differ from the private sector. While asset portfolio managers try to maximize asset returns over the holding period taking account of the risk, sovereign debt managers try to minimize debt-service-costs over a longer horizon taking into account the debt-servicecost volatility. Since most governments do not re-shuffle debt portfolios frequently and tend to hold debts up to maturity, sovereign debt managers are more concerned about debt-service-costs which directly affect fiscal budget rather than day-to-day fluctuations in the market value of debt portfolio. Hence, in the present paper, we assume that the debt-service-cost risk is a primary concern of the government debt management.

Note that the debt-service-cost of a debt portfolio in any given year depends upon the realizations of interest rates and debt issuance mixes up to that year. For instance, the cost of debt portfolio in the next year depends upon the decision made this year and the realizations of the stochastic variables in the current and next year. Given the government borrowing requirements over debt management horizon and the description of stochastic processes of random variables during the horizon, we can solve the above problem to identify an optimal debt strategy. More specifically, once the government's fiscal requirement over debt management horizon is given, the first step in benchmarking is to identify the expected cost-risk trade-off over various borrowing strategies satisfying the financing requirements. This step corresponds to identifying decision choice sets $D^{1}, D^{2} \ldots$ into the future. An efficient portfolio set at the end of the

\footnotetext{
${ }^{4}$ See Hahm (1999) for detailed discussions of various risks that need to be considered in sovereign debt management.

${ }^{5}$ An example of the control function is to minimize the gap from a target value-at-risk (VaR).
} 
debt management horizon is derived as a summary of the expected cost-risk trade-off based upon full-blown term structure simulations over the horizon. As a next step we employ a control function $f$, and based upon exogenously given control targets, an optimal benchmark portfolio is identified from the efficient portfolio set.

\subsection{Derivation of Efficient Portfolio Set}

Suppose that we are at the end of year $t$, and the government debt management horizon is $N$ years. The forecast of annual primary budget deficits during the debt management horizon is given exogenously and denoted by $\left\{P_{t+1}, P_{t+2}, \ldots \ldots P_{t+N}\right\}$. The government is considering a combination of $1,2,3, \ldots J$-year bonds to finance the primary budget deficits and to refinance maturing debts given the existing debt portfolio at the end of year $t$. A borrowing strategy can be denoted as a combination of those $J$ different maturity bonds and represented as a vector of weights, $\boldsymbol{w}=\left(w_{1}, w_{2}, \ldots w_{J}\right)$, which sum to unity. We assume that each borrowing strategy is time-invariant implying that under a borrowing strategy same weights of respective maturity bonds are maintained throughout the debt management horizon. ${ }^{6}$

Note that the existing government debt portfolio at the end of year $t$ is summarized as a vector $\boldsymbol{Z}_{t}=\left(z_{t}^{1}, z_{t}^{2}, z_{t-1}^{2}, z_{t}^{3}, z_{t-1}^{3}, z_{t-2}^{3}, \ldots, z_{t-i}^{j}, \ldots z_{t-J+1}^{J}\right)$, where a typical element $z_{t-i}^{j}$ is the balance of $j$-year bond issued in the year $t$ - $i$. Now, for a given borrowing strategy $w$, the government's total financing requirement for the next year, $B_{t+1}$, can be represented as the sum of primary budget deficit $P_{t+1}$ and the refinancing amount $\theta Y_{t+1}$, where $\theta$ is the fraction of refinancing $(0<\theta<1)$ and $Y_{t+1}$ is the sum of principals of maturing debt and interest costs to be paid in the year $t+1$ :

$$
B_{t+1}=P_{t+1}+\theta Y_{t+1}
$$

where $Y_{t+1}=\left[\left(z^{1}{ }_{t}+i^{1}{ }_{t} z_{t}{ }_{t}\right)+\left(z^{2}{ }_{t-1}+i_{t-1}^{2} z_{t-1}^{2}+i_{t}^{2} z_{t}^{2}\right)\right.$

\footnotetext{
${ }^{6}$ In principle, the borrowing strategy itself could be a dynamic one where the issuing mix of different maturity bonds may change year by year. However, for numerical tractability, and considering that sovereign debt management horizon is typically longer and the benchmarking itself is an effort to identify a medium to long-term target portfolio, we assume that borrowing strategies are time-invariant over the debt management horizon.
} 


$$
\begin{aligned}
& +\left(z_{t-2}^{3}+i_{t-2}^{3} z_{t-2}^{3}+i_{t-1}^{3} z_{t-1}^{3}+i_{t}^{3} z_{t}^{3}\right)+\ldots \ldots \\
& \left.+\left(z_{t-J+1}^{J}+i_{t-J+1}^{J} z_{t-J+1}^{J}+i_{t-J+2}^{J} z_{t-J+2}^{J}+\ldots \ldots+i_{t}^{J} z_{t}^{J}\right)\right]
\end{aligned}
$$

Note that $i_{t}^{j}$ is the interest rate on the $j$-year bond issued in the year $t$. We are assuming that a constant fraction of the principal amounts of maturing bonds as well as interest payments on all existing bonds is refinanced every year, and the remaining fraction is repaid from the government budget. Under the borrowing strategy $w$, the actual issuing amount for $J$ respective maturity bonds in the year $t+1$ can be computed as:

$$
\left(z^{1}{ }_{t+1}, z_{t+1}^{2}, z_{t+1}^{3}, \ldots z_{t+1}^{J}\right)=B_{t+1}\left(w_{1}, w_{2}, \ldots w_{J}\right)
$$

Now by the same logic, the total financing requirement for the year $t+2$ and the actual issuing amount for each bond in the year $t+2$ under the time-invariant borrowing strategy $\boldsymbol{w}$ can be represented as:

$$
B_{t+2}=P_{t+2}+\theta Y_{t+2}
$$

where

$$
\begin{aligned}
Y_{t+2} & =\left[\left(z^{1}{ }_{t+1}+i^{1}{ }_{t+1} z^{1}{ }_{t+1}\right)+\left(z^{2}{ }_{t}+i^{2}{ }_{t} z^{2}{ }_{t}+i^{2}{ }_{t+1} z^{2}{ }_{t+1}\right)\right. \\
& +\left(z^{3}{ }_{t-1}+i^{3}{ }_{t-1} z^{3}{ }_{t-1}+i^{3}{ }_{t} z^{3}{ }_{t}+i^{3}{ }_{t+1} z^{3}{ }_{t+1}\right)+\ldots \ldots \\
& \left.+\left(z_{t-J+2}^{J}+i_{t-J+2}^{J} z_{t-J+2}^{J}+i_{t-J+3}^{J} z_{t-J+3}^{J}+\ldots \ldots+i_{t+1}^{J} z_{t+1}^{J}\right)\right]
\end{aligned}
$$

$$
\text { and } \quad\left(z^{1}{ }_{t+2}, z^{2}{ }_{t+2}, z^{3}{ }_{t+2}, \ldots z_{t+2}^{J}\right)=B_{t+2}\left(w_{1}, w_{2}, \ldots w_{J}\right)
$$

Note that we are at the end of year $t$ and $B_{t+2}$ is a random variable as interest rates in the year $t+1,\left(i_{t+1}^{1}, i_{t+1}^{2}, \ldots i_{t+1}^{J}\right)$ cannot be observed at $t$. Note also that the actual amount of bond issuance in the year $t+2$ is determined by the borrowing amount in the year $t+1$. Hence, the issuing amount of each bond in any given year is a function of the borrowing strategy itself as well as the realization of the term structure of interest rates up to that year. The process can be repeated until the year $t+N$, and a specific debt portfolio will emerge depending upon the path of term structures realized during the $N$ years and given a specific borrowing strategy. 
Above discussion indicates that, given a stochastic process of term structure of interest rates and given a borrowing strategy, we can obtain a conditional distribution of debtservice-costs on the debt portfolio which will emerge at the end of the horizon by conducting simulations on the term structure of interest rates. Each borrowing strategy can be characterized by the mean and standard deviation of debt-service-costs and/or by the cost at the $95 \%$ percentile associated with the resulting debt portfolio. By conducting full-blown simulations across numerous borrowing strategies, we can represent all period-end portfolios in the space of mean and standard deviation so that we can identify the efficient portfolio set conditional upon existing debt portfolio.

[Insert Figure 1 here]

Then will there be tradeoffs between the mean and volatility of debt-service-costs? As shown in figure 1, with usual upward sloping yield curves, short-term borrowing implies lower expected debt-service-costs but higher volatilities than long-term financing, and this is because, first, short-term interest rates are more volatile than longterm interest rates, and second, short-term financing requires more frequent refinancing over the debt management horizon. For example, table 1.a shows historical means and standard deviations of yields on various maturity U.S. treasury bonds computed from daily data over the period of 1976 to1997, which clearly indicates that the yield to maturity of a longer-term bond tends to have a higher mean but less volatility. Also as shown in table 1.b, Kim and Hahm (2000) showed that, based upon the U.S. term structure simulation, refinancing with shorter-term bonds tends to have a lower expected average annual debt-service-cost but higher standard deviation of the average debtservice-cost. ${ }^{7}$ Hence, across possible debt portfolios corresponding to respective combinations of different borrowing strategies, there will be a tradeoff between expected value and standard deviation of debt-service-costs. We can obtain the efficient portfolio set by selecting portfolios that yield lowest expected costs at each level of standard deviation. ${ }^{8}$

\footnotetext{
7 The expected average annual debt-service-cost will be invariant across different borrowing strategies if pure expectations hypothesis of term structure holds tightly. However, under the liquidity preference theory, it is easy to show that longer-term financing tends to be associated with a higher expected average annual debt-service-cost but with a lower conditional variance of the average annual cost.

${ }^{8}$ Note that the dynamic nature of our multi-period problem makes analytical derivation of efficient portfolio almost impossible. Hence, we focus on numerical solutions in the present study.
} 
[Insert Table 1 here]

\subsection{Identification of Benchmark Portfolio}

Given the efficient portfolio set above, the next step is to identify an optimal benchmark portfolio among the efficient set. Not only a target measure for debt-service-cost risk but other exogenous risk targets can also be employed to constitute the control function $f$ in equation (2) above. Note that the efficient portfolio set in the previous section is derived based upon debt-service-cost variations, and hence, the analysis does not incorporate other risk factors that the government may also want to control. The control function can be established to consider those exogenous medium-term targets in addition to debt-service-cost risk, such as liquidity risk, sovereign asset structure, capital market development, and so forth.

In controlling the level of debt-service-cost risk, a natural risk target is the cost-at-risk $(\mathrm{CaR})$, which is defined as the maximum possible yearly interest cost that can be realized in a given year at a given (for instance, 95\%) confidence level. ${ }^{9}$ Controlling debt-service-cost risk by $\mathrm{CaR}$ is consistent with recent theories of portfolio selection with a short-fall constraint to control down-side risk. Suppose that the government has an explicit maximum tolerable cost-at-risk limit, then a feasible portfolio set can be identified from the CaR limit. Note that the $95 \% \mathrm{CaR}$ can be defined as in equation (7) in the case of a normally distributed debt-service-cost. By rearranging equation (7), we can easily obtain equation (8), which indicates that $\mathrm{CaR}$ is represented as a downward sloping line with the slope of -1.645 in the plane of expected value and standard deviation of annual debt-service-cost. The value of the line at the vertical axis (expected cost axis) is the $95 \% \mathrm{CaR}$. Note that $\mu$ and $\sigma$ represents expected value and standard deviation of annual debt service cost, respectively.

$$
\begin{aligned}
& C a R=\mu+1.645 \sigma \\
& \mu=C a R-1.645 \sigma
\end{aligned}
$$

\footnotetext{
${ }^{9}$ While the value-at-risk (VaR) is measured based upon the market value of underlying portfolios, the $\mathrm{CaR}$ is an application of VaR on debt-service-cost. See Jessen (1998a, b) and Kim and Hahm (2000) for detailed discussions of $\mathrm{CaR}$ and applications to sovereign debt management.
} 
Figure 2 describes a hypothetical efficient portfolio set and the CaR line. The efficient frontier is represented as a downward sloping curve where debt portfolios only above the curve can be obtained. For instance, if the government establishes a maximum tolerable $95 \% \mathrm{CaR}$ at $\mathrm{CaR}_{1}$, then the feasible portfolio set $D$ in equation (2) is now identified as a range constrained by the downward sloping maximum tolerable CaR line starting from $\mathrm{CaR}_{1}$ at the vertical axis and the efficient frontier. While portfolio $\mathrm{A}$ is an attainable efficient portfolio, it is not a feasible portfolio since it is located above the maximum tolerable $\mathrm{CaR}_{1}$ line indicating that its implied $95 \% \mathrm{CaR}$ is higher than $\mathrm{CaR}_{1}$ under the assumption of a normally distributed debt-service-cost. Portfolio $\mathrm{C}$ is located inside the feasible choice set, and hence, can become a candidate for the benchmark portfolio.

\section{[Insert Figure 2 here]}

The final step is to identify a benchmark portfolio from the feasible choice set. Given the feasible efficient portfolio set and exogenous risk targets, a portfolio which minimizes deviations from the exogenous medium-term targets can be selected as the benchmark portfolio. That is, the benchmark portfolio is identified by minimizing a penalty function defined as a weighted average of deviations from the respective medium-term risk targets. For instance, in the absence of other exogenous medium-term targets and under the objective of minimizing the $95 \% \mathrm{CaR}$, we can identify the benchmark portfolio by shifting down the CaR line in figure 2. In figure 2, portfolio B is the benchmark portfolio, where the CaR line is tangent to the efficient frontier. Note that, while the short-run fluctuation in the market value of the government debt portfolio is not direct concerns in sovereign debt management, many countries are explicitly adopting duration targets in an attempt to control medium-term market risks as well as liquidity risks. Hence, alternatively, if the government considers an exogenous duration target in addition to the minimization of $\mathrm{CaR}$, we can apply the following penalty function to identify the optimal benchmark portfolio:

$$
\begin{aligned}
& \text { Minimize } \quad f=\rho \cdot\left|d u r-d u r^{*}\right| / d u r^{*}+(1-\rho) \cdot\left(C a R-C a R_{m}\right) / C a R_{m} \\
& \text { where } \rho: \quad \text { relative weight attached to the duration target }(0 \leq \rho \leq 1) \\
& \text { dur : portfolio duration } \\
& d u r^{*}: \quad \text { exogenously given medium-term target duration }
\end{aligned}
$$


CaR: $\quad 95 \%$ cost-at-risk $(\mathrm{CaR})$

$C a R_{m}: \quad$ minimum $\mathrm{CaR}$ among all attainable portfolios

Note again that the optimal borrowing strategy is simultaneously identified with the benchmark portfolio. That is, we can choose a borrowing strategy which will end up with a portfolio on the feasible portfolio set, where the implied duration of the portfolio is closest to the exogenous medium-term target and the associated CaR value is lowest. Likewise, we can add other exogenous medium-term targets such as the slope of maturity profile into the penalty function if we want those factors to be reflected in identifying the optimal benchmark portfolio. The optimal portfolio chosen in this way could function as a benchmark against which actual government debt portfolio and specific borrowing programs can be evaluated.

\section{Applications to Korean Government Debt Portfolios}

\subsection{Basic Premises}

In this section we apply above benchmarking framework to actual Korean sovereign debt portfolios. Implementation of the framework is based upon the following basic assumptions.

\section{A. Debt Management Horizon}

Debt management horizon is an important input to benchmarking. Throughout the paper we assume that 5-year period is a relevant debt management horizon for Korea considering the current practice that the government prepares and announces a fiscal management plan over the 5-year horizon. Not only the official 5-year budget forecasts are available, but also the macroeconomic forecast beyond 5 years is highly unreliable.

\section{B. Measurement of the Cost}

Considering the current practice of government budget accounting in Korea, and the observation that the Korean government does not frequently engage in market transactions, we adopt cash flow cost measures rather than marked-to-market cost measures. Also as a measure of the annual debt-service-cost, we use relative cost 
(interest expense / debt outstanding) rather than the cost in absolute amount. Although the Korean government has not adopted accrual accounting system yet, interest expenses on discount bonds were amortized over the life of the bond, and in the case of coupon bonds issued at prices different from par values, initial capital gains or losses were also amortized.

\section{Domestic versus External Debt Portfolios}

Given the differential objectives of domestic and external sovereign debt issuance, domestic (mostly the Korean won denominated) debt portfolios were separately dealt with external (foreign currency denominated) debt portfolios. ${ }^{10}$ Also we adopted differential base currencies across external and domestic portfolios. While it is natural to choose the Korean won as a base currency for domestic debt portfolio benchmarking, the U.S. dollar was used for external government debt analysis because most of the external debt has been accumulated as official foreign exchange reserves that are denominated in foreign currencies and the external government debt is not being repaid from the fiscal budget.

\section{Asset-Liability Management Considerations}

In the case of external government debt, an asset-liability management (ALM) approach is possible with official foreign exchange reserves as a counterpart. However, the foreign reserve at the Bank of Korea (BOK) is currently much larger in size relative to the external debt, and hence, it is difficult to directly apply ALM approaches due to the size differential. Furthermore, the foreign exchange reserve at the central bank is maintained to meet emergency liquidity needs associated with external liabilities of the country as a whole including private firms and financial institutions. Hence, in the following analysis, we apply our benchmarking framework to external sovereign debt portfolios without explicitly considering foreign exchange reserve portfolios. However, in the spirit of the asset-liability management, we indirectly take into account the structure of the BOK reserve portfolio when exogenous target duration is established for external government debt.

\footnotetext{
10 The Korean government has not issued foreign currency denominated debts for the purpose of financing budget deficits, and this practice is expected to continue in the future. Sovereign external debts denominated in foreign currencies have mainly been a vehicle to procure foreign exchange liquidity during the recent financial crisis episode.
} 


\section{E. Government Guarantees}

In the present study we focus on direct debt portfolios of the government. In principle, the government guarantees can also be pooled with direct debts by applying certain conversion probabilities. However, it is not easy to measure the probability of the guarantee being exercised, which will also change over time. Hence, the government guarantees were excluded in the following analysis.

\subsection{The Data: Basic Profiles of Government Debt Portfolios in Korea}

\section{A. Direct Domestic Government Debt}

Table 2 summarizes basic profiles of direct domestic central government debts in Korea by category as of March 2000. ${ }^{11}$ Treasury bond accounts for the largest share of the domestic debt portfolio and Foreign Exchange Stabilization Fund bond (FESF), Grain Security, National Housing bonds also represent relatively big shares. Note that the average duration of the central government domestic debt is 2.156 years, which is relatively short in comparison to other countries. As shown in table 4 below, the average duration of domestic sovereign debt portfolios of European countries is around 4.0 years. Shorter duration implies a higher debt-service-cost risk as more frequent refinancing is necessary and as changes in market interest rates are reflected relatively fast into the debt-service-cost. Short durations, however, imply a lower market-value risk as market value fluctuations due to the interest rate variation are relatively small for short duration portfolios. Hence, the domestic debt portfolio of the Korean government is characterized with a relatively high debt-service-cost risk, but with a relatively low market-value risk.

\section{[Insert Table 2 here]}

\footnotetext{
11 By law, the government can issue eight different government bonds. However, only six bonds are currently being issued: Grain Securities, Foreign Exchange Stabilization Fund (FESF) Bonds, Treasury Bonds, National Housing (NH) Bonds of Type I and Type II, and Land Compensation Bonds. Among these, the first three are issued in the market through competitive auctions, while the rest are issued outside the market.
} 


\section{B. Direct External Government Debt}

Table 3 shows basic profiles of the central government external debt by counterparts as of March 2000. Note that the duration of external sovereign debt portfolio is only 1.694 years, which reflects that many of the debt instruments are floating rate debts. The duration is again relatively short in comparison to other countries. For instance, the average duration of external sovereign debt portfolios of major countries is around 2.4 years (1.8 years in terms of target durations) as shown in table 4 below.

\section{[Insert Table 3 here]}

Again relatively short duration implies that the Korean external sovereign debt portfolio is characterized by a relatively high debt-service-cost risk, but with a lower marketvalue risk. Note that we have emphasized debt-service-cost risk as a more important risk that needs to be actively managed at the sovereign level. In this sense, issuing more fixed rate long-term debt, or repaying short-term and floating rate debts first would be desirable debt policies. However, it is not clear at all exactly what portfolio structure is optimal and be targeted ultimately, which we now focus on in the following benchmarking analysis.

[Insert Table 4 here]

\subsection{Benchmark Portfolios and Optimal Borrowing Strategies}

This section conducts empirical analysis to identify efficient cost-risk trade-offs and optimal benchmark portfolios. The analysis was conducted based upon the actual Korean government debt data as of March 20, 2000. The planning period or debt management horizon was assumed to be 5 years, and the decision interval or time unit of the analysis was assumed as yearly.

\section{A. Efficient Frontier and Benchmark Portfolio for Domestic Government Debt}

By following the procedure described in section 2.1 above, the efficient frontier set for domestic government debt as of the end of 2004 was derived as a summary of the 
expected cost-risk trade-off. For the primary budget deficit scenario over the debt management horizon, we adjusted the government budget deficit projection as of the end of 1999 to convert them into primary deficit figures excluding interest rate expenses. ${ }^{12}$ The primary budget deficit projection is given in table 5.a. For yield curve simulations, we employed a random bootstrapping method as in Kim and Hahm $(2000)^{13}$, and the simulation was based upon daily yield curve data on Korean government bonds from January 1996 to March 2000. More sophisticated simulation methods such as Monte Carlo could be used if we have enough past data accumulated for term structure of interest rates, which is not the case for Korea. In the simulation, we assumed that $100 \%$ of maturing debt principals and interest expenses are refinanced. For each of the borrowing strategies, we conducted yield curve simulations 1,000 times to compute the mean, standard deviation, and the $95 \% \mathrm{CaR}$ of the period end portfolio at the end of 2004. The simulation result is summarized in figure 3, which shows a clear negative trade-off between expected cost and risk. Note again that the efficient frontier is conditional upon the existing debt structure as of March 20, 2000.

[Insert Figure 3 here]

Given the efficient frontier, the next step is to identify a benchmark portfolio among the efficient portfolio set. As noted above, in this step, it is essential to have a set of wellarticulated medium-term targets. The medium-term targets function as a vehicle to translate exogenous considerations into explicit factors in identifying the benchmark portfolio. In principle, any factor actually considered in sovereign debt management can be included as a medium-term target. However, in the present study, we consider portfolio duration as an exogenous medium-term target in addition to the $95 \% \mathrm{CaR}$ to simplify our analysis in the benchmarking process.

We can consider two factors in establishing the exogenous medium-term target duration

\footnotetext{
${ }^{12}$ The numbers were derived from the official medium-term fiscal plan of the Ministry of Planning and Budget (1999) and the negative numbers denote primary budget surplus.

${ }^{13}$ Kim and Hahm (2000) showed that a trade-off exists between the debt-service-cost and risk of various financing strategies based upon the U.S. yield curves employing a hypothetical portfolio. The difference between Kim and Hahm (2000) and the present paper is that, first, we derive efficient frontiers based upon the actual government debt structure and interest and maturity profiles, and second, we also derive efficient frontier for domestic debts based upon domestic yield curves, and most critically, we provide a benchmarking framework and identify optimal borrowing strategies while Kim and Hahm just characterizes the cost-risk trade-off for external debt based upon the CaR and efficient frontier analyses.
} 
for domestic debt. First criterion is the implied duration of the steady state debt portfolio to be obtained under the government funding strategy to develop government bond markets. Fostering capital markets by developing government bond markets is an important consideration in sovereign debt management, which is exogenous to our debtservice-cost simulations. The Korean government has preferred the 25\% 1-year, 50\% 3 year, and 25\% 5-year mix of fixed rate bond issuance in an effort to develop the 3-year treasury bond as a benchmark issue. Simple analysis shows that the implied duration of the steady state portfolio under the above funding strategy is 1.7 years. The second factor is the duration of domestic government debt portfolios in other countries. Note that the average duration is 4.0 in the case of European countries as shown in table 4. Based on these two criteria, we set the medium-term target duration for domestic debt portfolio at 2.85, which is the average of 1.7 and 4.0 .

Based upon the target duration, an optimal benchmark portfolio can be identified from the efficient set by minimizing the penalty function described in equation (9) above. The penalty function indicates that a portfolio whose implied duration is closest to the medium-term target duration and whose cost-at-risk is smallest will be chosen as the optimal portfolio. To obtain the benchmark portfolio, we also need to decide the weights of the duration gap and $\mathrm{CaR}$ in the penalty function. Based upon the observation that sovereign debt managers do not frequently trade in the market, we assume that the duration, a market risk measure, is relatively less important than $\mathrm{CaR}$ - a measure of debt-service-cost risk. Hence, we set the penalty weights for duration gap relatively smaller in the range from zero to $20 \%$.

The optimal borrowing strategies obtained under different duration weights are summarized in table 5. Note that the case of zero weight for duration gap corresponds to the case of minimizing $\mathrm{CaR}$ without exogenous targets. Under the case, the optimal debt issuing mix is $13 \%$ 1-year, $1 \%$ 3-year and $86 \%$ 5-year bond, which implies that, while costly, it would be better to take less risk by issuing longer-term debts from the perspective of minimizing the $95 \% \mathrm{CaR}$. For non-zero duration weights, approximately $30 \%$ 1-year, 30\% 2-year and 40\% 3-year mix seems to be an optimal borrowing strategy. The benchmark portfolio to be obtained under the optimal borrowing mix in the case of duration weight $10 \%$ was shown in figure 3.

[Insert Table 5 here] 


\section{B. Efficient Frontier and Benchmark Portfolio for External Government Debt}

In the case of external government debts, in a rigorous sense, it is necessary to conduct a full-blown simulation of yield curves, exchange rates, and sovereign risk premia for Korean government debts. However, multivariate simulations simultaneously covering all those variations are not feasible and extremely costly. Hence, we focus on the yield curve simulation as in domestic debt analysis. As noted above, the U.S. dollar was chosen as a base currency in the benchmarking analysis of external government debt and simulations were conducted based on random bootstrapping using daily U.S. yield curve data from January 1990 to December 1999. The number of term structure simulation was again 1,000 for each borrowing strategy, and the confidence level for $\mathrm{CaR}$ was set at $95 \%$. Based on the observation that the Korean government has not issued foreign currency debt to finance budget deficits, we assumed that no financing requirements are arising from primary budget deficits in the case of external debt. We also assumed that $50 \%$ of maturing debt principals and interest expenses are refinanced every year as the Korean government plans to gradually retire external sovereign debt in the near future. Figure 4 shows the simulated portfolios and efficient frontier for Korean external government debts, which again shows a negative slope as in the case of domestic debts denoting the existence of a trade-off between debt-service-cost and risk.

[Insert Figure 4 here]

The benchmark portfolio for external debt has also been computed using the penalty function in equation (9). The exogenous medium-term target duration for external debt portfolio was obtained by considering following factors: first, the duration of the BOK investment portfolio of foreign exchange reserves, which was 2.4 as of October 1998. Second, other countries' target durations on external sovereign debt. As summarized in table 4, many European countries are maintaining their foreign currency debt durations in the range of 1 to 3 , where the average target duration is 1.8 . Hence, we chose 2.1, which is the average of 2.4 and 1.8, as the target duration in the case of external debt.

Table 6 shows the optimal borrowing strategies obtained under various duration weights. In the case of no duration target, the optimal borrowing mix is $81 \% 1$-year, 3\% 3-year, and $16 \%$ 5-year bond, implying that the cost is relatively more important in the cost-risk trade-off from the perspective of $\mathrm{CaR}$ minimization. However, when we give positive 
weights to duration gaps, the shares for the 3-year and 5-year bonds increase while the share of 1-year bond decreases. In the case of $5 \%$ duration weight, the optimal debt issuing mix is 69\% 1-year, 6\% 3-year, and 25\% 5-year bond. The benchmark portfolio associated with the optimal borrowing mix under $5 \%$ duration weight was shown in figure 4 .

[Insert Table 6 here]

\section{Summary and Concluding Remarks}

In this paper we provided a benchmarking framework for government debt, which is based upon recent developments in the risk management theory, and yet, easily applicable in actual debt management practices. The framework builds itself upon the cost-risk trade-off summarized as efficient frontiers constructed over the expected value and variability of future debt-service-costs. The debt-service-cost risk is a risk actively managed in most countries and we employed $\mathrm{CaR}$, a risk measure of debt-service-cost risk to develop a penalty function so that an optimal benchmark portfolio can be identified. The benchmark portfolio effectively defines a borrowing strategy so that the government can adjust its debt portfolio toward the target structure in financing annual borrowing requirements over the debt management horizon. This paper also applied the benchmarking framework to actual Korean sovereign debt data and identified optimal borrowing strategies for both domestic and external government debts.

Of course the present study suffers from a set of limitations. Note that the present framework emphasizes the management of debt-service-cost risk. However, there are other important risks that should be managed in actual debt management, such as liquidity / refinance risk, market risk and so forth. While the framework was constructed in such a way that these other risks can be reflected as exogenous medium-term targets and these targets can be included as additional factors in the penalty function, this indirect consideration may not be enough. For instance, liquidity risk and debt-servicecost risk often imply conflicting implications for optimal debt policy, and it is difficult to conclude which risk should be managed with a higher priority. Therefore, one must be careful in deciding the relative importance, and hence, in applying the present benchmarking framework. 
Note also that the present framework identifies a time invariant borrowing strategy associated with the optimal benchmark portfolio. However, in reality, the government may want to consider risks associated with a specific dynamic borrowing program where borrowing mix varies over the debt management horizon. While the optimal dynamic borrowing strategy cannot be identified with our framework, it is possible to trace evolutions of debt portfolios and their risk characteristics implied by a specific dynamic borrowing program. In this way, alternative dynamic borrowing strategies can be evaluated against the steady state optimal benchmark portfolio identified in the present framework, and government debt managers would be able to choose an ideal dynamic borrowing strategy based upon the evaluations. 


\section{References}

Breeden, D. (1979), “An Intertemporal Asset Pricing Model with Stochastic Consumption and Investment Opportunities," Journal of Financial Economics, Vol. 7, pp. 265-96.

Carracedo, M. and P. Dattels (1997), "Survey of Public Debt Management Frameworks in Selected Countries", in Coordinating Public Debt and Monetary Management, edited by V. Sundararajan et al., International Monetary Fund, pp.96-162.

Cassard, M. and D. Folkerts-Landau (1997), "Risk Management of Sovereign Asset and Liability," IMF working paper WP/97/166.

Claessens, S. (1992), "The Optimal Currency Composition of External Debt: Theory and Applications to Mexico and Brazil," The World Bank Economic Review, Vol. 6., No. 3. September.

Claessens, S., Kreuser J., Seigel L. and R. Wets (1995), "A Strategic Approach to Asset/Liability Management in Developing Countries," Research Proposal, The World Bank, July.

Claessens, S., Kreuser J., Seigel L. and R. Wets (1998), "A Tool for Strategic Asset and Liability Management," World Bank working paper, Research Project Ref. No. 681-23.

Cohen, D. (1991), Private Lending to Sovereign States, Cambridge, MA: MIT Press

Eaton, J. (1992), “Sovereign Debt: A Primer,” World Bank working paper, \#WPS 855, February.

Jessen, L. K. (1998a), "Managing Refinancing Risk in the Case of Benchmark and Opportunistic Borrowing," paper presented in the OECD workshop on Debt Management, May.

Jessen, L. K. (1998b), "The Interest and Refinancing Risk on Domestic Government Debt - Cost at Risk," mimeo, Denmark National Bank.

Hahm, J. (1999), "The Framework and Future Directions of Sovereign External Debt Management in Korea," KDI Policy Studies, No. 99-04, Korea Development Institute. (in Korean)

Kroner, K. and S. Claessens (1991), "Optimal Dynamic Hedging Portfolios and the Currency Composition of External Debt," Journal of Money and Finance, Vol. 
10, pp. 131-148.

Kim, J. and J. Hahm (2000), "Sovereign Debt Risk Management using Cost-at-risk Concept," Korean Journal of Finance, Vol. 13, No. 2, pp. 277-309. (in Korean)

Markowitz, H. M. (1952), "Portfolio Selection," Journal of Finance, Vol. 7, pp. 77-91.

Merton, R. C. (1971), "Optimum Consumption and Portfolio Rules in a Continuous Time Model," Journal of Economic Theory, Vol. 3, pp. 373-413.

Ministry of Planning and Budget, Korea (1999), Medium-term Fiscal Plan.

World Bank (1999), Second Sovereign Debt Management Forum: Compilations of Presentations, Financial Products and Services Department, World Bank. 
$<$ Table 1> Trade-offs between Expected Debt-Service-Cost and Risk

(Based upon the U.S. term structure)

a. Yield to Maturities on the U.S. Treasury Bonds (1976-1997, \% p.a.)

\begin{tabular}{|c|c|c|c|c|}
\hline Maturity & 1 year & 2 year & 3 year & 5 year \\
\hline Mean & 7.810 & 8.172 & 8.333 & 8.575 \\
Standard Deviation & 2.895 & 2.725 & 2.607 & 2.460 \\
\hline
\end{tabular}

Source: Kim and Hahm (2000)

b. Simulated Mean and Standard Deviation of Average Annual Debt-Service-Cost

\begin{tabular}{|c|c|c|}
\hline Borrowing Strategies for 12 Year Horizon & Mean & Std. dev \\
\hline Rolling over with 1 Year Bonds & 7.947 & 3.013 \\
2 Year Bonds & 8.210 & 1.953 \\
3 Year Bonds & 8.247 & 1.485 \\
5 Year Bonds & 8.247 & 1.029 \\
\hline
\end{tabular}

Source: Kim and Hahm (2000)

<Table 2> Basic Profiles of Domestic Government Debts in Korea (as of March 2000)

\begin{tabular}{|l|r|r|r|r|r|}
\hline \multicolumn{1}{|c}{ Category } & $\begin{array}{c}\text { Nominal } \\
\text { Value }\end{array}$ & $\begin{array}{c}\text { Market } \\
\text { Value }\end{array}$ & $\begin{array}{c}\text { Average } \\
\text { Price }\end{array}$ & Duration & $\begin{array}{c}\text { Modified } \\
\text { Duration }\end{array}$ \\
\hline Bank of Korea Borrowing & 789.0 & 786.1 & $99.63 \%$ & 1.428 & 1.392 \\
Basic Science Research Fund & 135.0 & 135.1 & $100.06 \%$ & 0.066 & 0.065 \\
Compensation Bond & 0.2 & 0.2 & $93.72 \%$ & 0.646 & 0.586 \\
Export Insurance Fund & 620.0 & 619.3 & $99.89 \%$ & 0.069 & 0.067 \\
FESF Bond & $4,599.9$ & $4,213.7$ & $91.60 \%$ & 1.188 & 1.099 \\
Grain Security & $3,002.9$ & $2,330.9$ & $77.62 \%$ & 2.293 & 2.067 \\
Korea Teachers Pension Fund & 655.0 & 654.5 & $99.92 \%$ & 0.076 & 0.073 \\
Long-term Industry Bond & 114.2 & 74.6 & $65.36 \%$ & 3.701 & 3.300 \\
Nat'l Health Improv. Fund & 130.1 & 130.3 & $100.15 \%$ & 0.109 & 0.106 \\
Nat'l Housing Bonds (I) & $12,396.4$ & $9,444.6$ & $76.19 \%$ & 2.409 & 2.165 \\
Nat'l Housing Bonds (II) & $3,263.1$ & 881.9 & $27.03 \%$ & 10.909 & 9.749 \\
Treasury Bond & $33,533.1$ & $33,356.2$ & $99.47 \%$ & 2.075 & 2.002 \\
\hline \multicolumn{1}{|c|}{ Total } & $59,239.0$ & $52,627.3$ & $88.84 \%$ & 2.156 & 2.028 \\
\hline
\end{tabular}

Source: Ministry of Finance and Economy, Republic of Korea 
<Table 3> Basic Profiles of External Government Debts in Korea (as of March 2000)

(billion won)

\begin{tabular}{|l|c|c|c|c|c|}
\hline Counterpart & Nominal Value & Market Value & Average Price & Duration & $\begin{array}{c}\text { Modified } \\
\text { Duration }\end{array}$ \\
\hline ADB & $4,144.4$ & $4,150.4$ & $100.15 \%$ & 0.316 & 0.308 \\
FESF Bond & $4,486.7$ & $4,495.8$ & $100.20 \%$ & 5.126 & 4.980 \\
IMF & $6,121.4$ & $6,095.3$ & $99.57 \%$ & 1.864 & 1.835 \\
World Bank & $7,840.7$ & $7,842.3$ & $100.02 \%$ & 0.324 & 0.315 \\
\hline Total & $22,593.1$ & $22,583.8$ & $99.96 \%$ & 1.694 & 1.653 \\
\hline
\end{tabular}

Source: Ministry of Finance and Economy, Republic of Korea

<Table 4> Duration of Sovereign Debt Portfolios (1999-2000)

\begin{tabular}{|c|c|c|}
\hline Country & Domestic Debt Portfolio & External Debt Portfolio \\
\hline Australia & - & $(1-1.5)$ \\
Austria & 4.5 & - \\
Belgium & $4.2(3.75-4.75)$ & $2.2(0.75-2.25)$ \\
Denmark & $4.1(3.5-4.1)$ & $2.0(1.5-2.5)$ \\
Finland & 3.9 & - \\
Holland & $(4.0)$ & - \\
Italy & 2.5 & - \\
Portugal & 3.0 & 3.1 \\
Spain & 3.2 & - \\
Sweden & $(3.5)$ & - \\
UK & 6.8 & $2.4(1.8)$ \\
\hline Average & $4.0(3.9)$ & \\
\hline
\end{tabular}

Note: Figures in the parenthesis are target durations.

Source: World Bank 
$<$ Table 5> Optimal Borrowing Strategies for Domestic Government Debt

a. Primary Budget Deficit Scenario

(billion won)

\begin{tabular}{|c|c|c|c|c|c|}
\hline Year & 2000 & 2001 & 2002 & 2003 & 2004 \\
\hline Budget Deficit & 3,000 & -100 & $-3,400$ & $-6,700$ & $-9,600$ \\
\hline
\end{tabular}

b. Optimal Debt Issuing Mix

\begin{tabular}{|c|c|c|c|}
\hline Bond Maturity & 1 year & 3 year & 5 year \\
\hline No Duration Target (min. CaR) & $13 \%$ & $1 \%$ & $86 \%$ \\
\hline Duration Target: 2.85 & & & \\
Duration weight: $10 \%$ & $27 \%$ & $33 \%$ & $40 \%$ \\
Duration weight: $20 \%$ & $30 \%$ & $29 \%$ & $41 \%$ \\
\hline
\end{tabular}

$<$ Table 6> Optimal Borrowing Strategies for External Government Debt

\begin{tabular}{|c|c|c|c|}
\hline Bond Maturity & 1 year & 3 year & 5 year \\
\hline No Duration Target (min. CaR) & $81 \%$ & $3 \%$ & $16 \%$ \\
\hline Duration Target: 2.1 & & & \\
Duration weight: $5 \%$ & $69 \%$ & $6 \%$ & $25 \%$ \\
Duration weight: $10 \%$ & $64 \%$ & $11 \%$ & $25 \%$ \\
\hline
\end{tabular}


$<$ Figure 1> Expected Cost-Risk Tradeoffs of Short-term and Long-term Financing

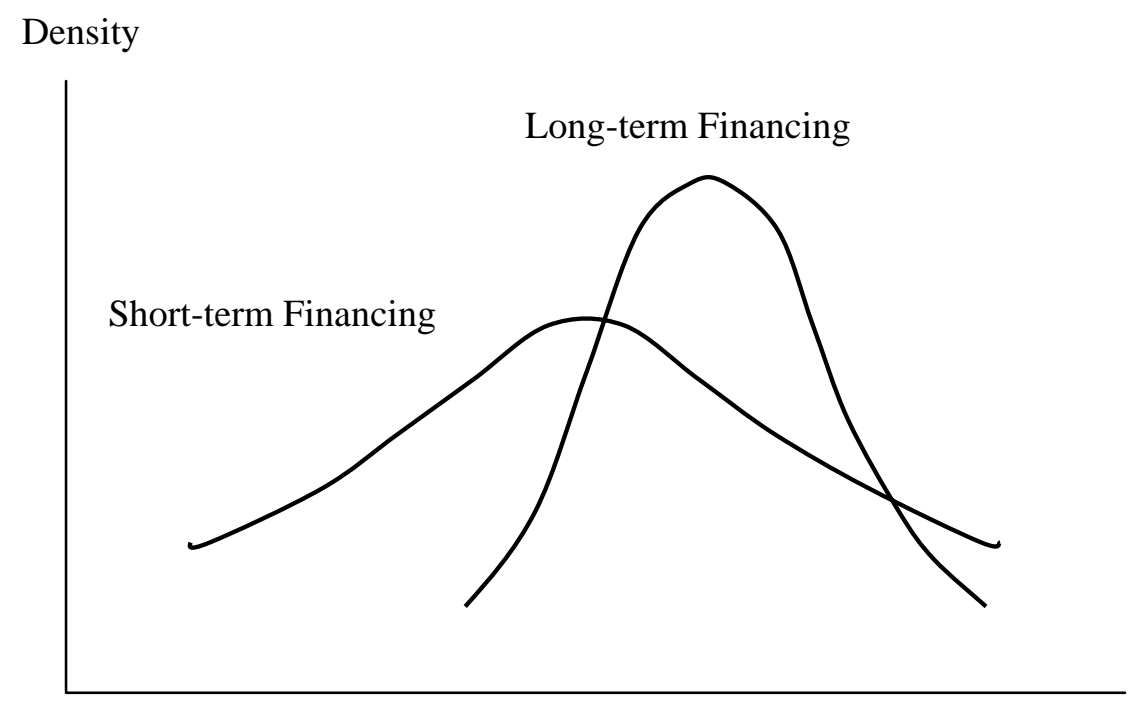

Debt Service Cost

$<$ Figure 2> Efficient Frontier and Cost-at-Risk $(\mathrm{CaR})$

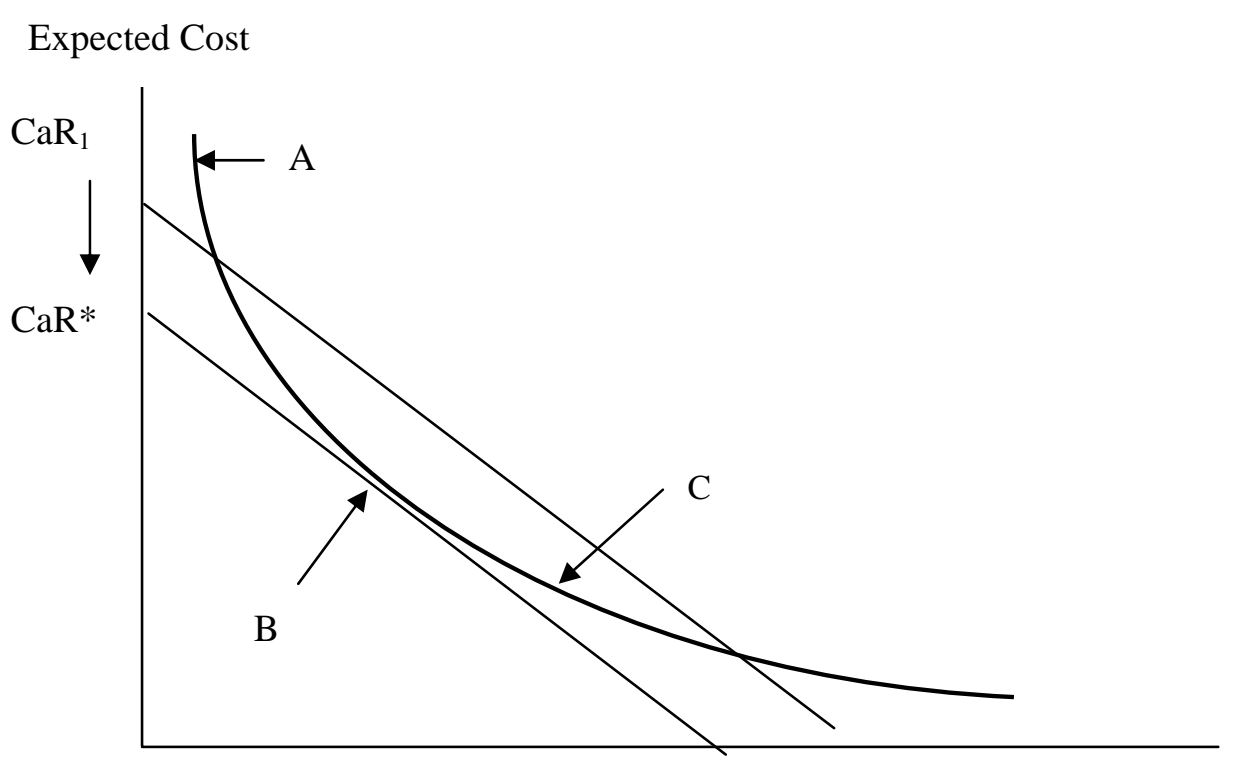

Standard Deviation 
<Figure 3> Efficient Frontier and Benchmark Portfolio for Domestic Debt

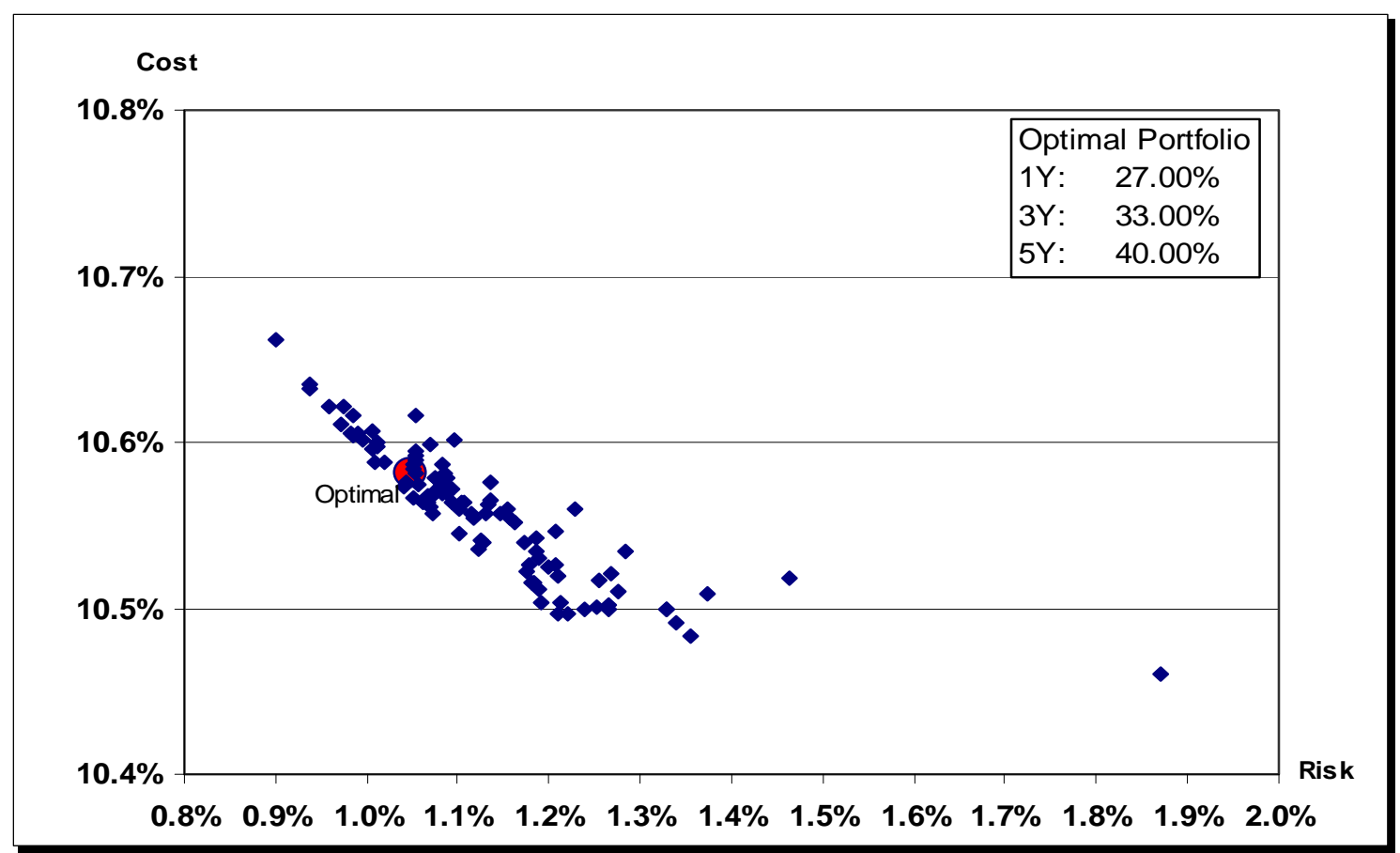

$<$ Figure 4> Efficient Frontier and Benchmark Portfolio for External Debt

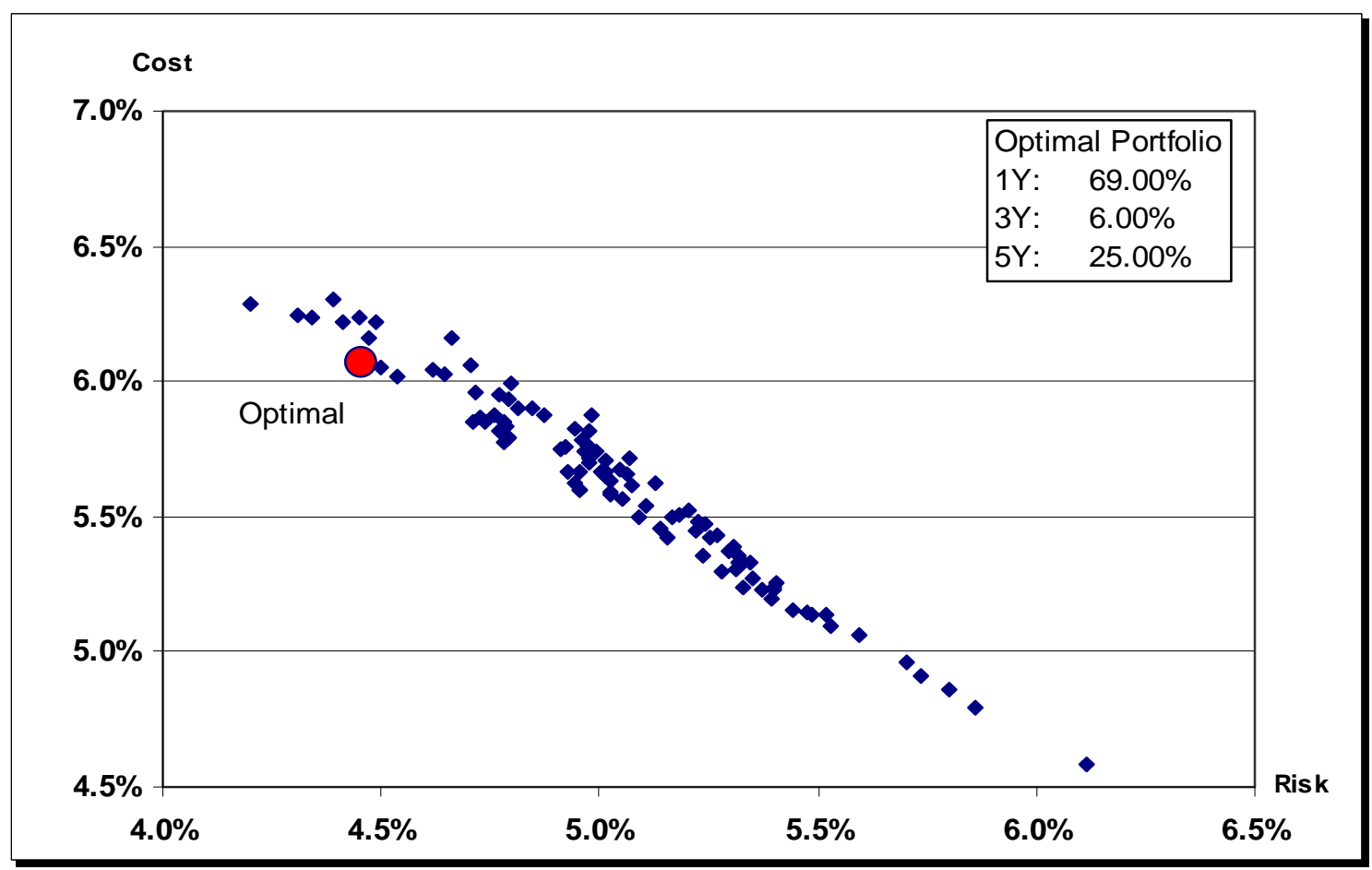

